\title{
Chronic inflammation drives glioma growth: cellular and molecular factors responsible for an immunosuppressive microenvironment
}

\author{
Edward T. Ha ${ }^{1}$, Joseph P. Antonios ${ }^{1}$, Horacio Soto ${ }^{1}$, Robert M. Prins ${ }^{1,3,4}$, Isaac Yang ${ }^{1,4}$, Noriyuki Kasahara ${ }^{2}$, \\ Linda M. Liau ${ }^{1,3,4}$, Carol A. Kruse ${ }^{1,3,4}$ \\ ${ }^{1}$ Department of Neurosurgery, David Geffen School of Medicine, University of California, Los Angeles, CA 90095, USA. \\ ${ }^{2}$ Department of Medicine, David Geffen School of Medicine, University of California, Los Angeles, CA 90095, USA. \\ ${ }^{3}$ Brain Research Institute, University of California, Los Angeles, CA 90095, USA. \\ ${ }^{4}$ Jonsson Comprehensive Cancer Center, University of California, Los Angeles, CA 90095, USA.
}

\section{A B S T R A C T}

This review examines glioma disease initiation, promotion, and progression with a focus on the cell types present within the tumor mass and the molecules responsible for the immunosuppressive microenvironment that are present at each step of the disease. The cell types and molecules present also correlate with the grade of malignancy. An overall "type 2" chronic inflammatory microenvironment develops that facilitates glioma promotion and contributes to the neo-vascularization characteristic of gliomas. An immunosuppressive microenvironment shields the tumor mass from clearance by the patient's own immune system. Here, we provide suggestions to deal with a chronically-inflamed tumor microenvironment and provide recommendations to help optimize adjuvant immune- and gene therapies currently offered to glioma patients.

Key words: Astrocytoma, glioma, immunotherapy, inflammation, microenvironment

\section{INTRODUCTION}

The World Health Organization (WHO) grade IV glioma is called glioblastoma, and is formerly termed glioblastoma multiforme (GBM) because its appearance can take on a variety of morphologic forms. GBM is the most common and lethal of all primary malignant brain tumors, and is responsible for over 13,000 deaths per year in the United States. ${ }^{[1]}$ The median survival is approximately 15 months. ${ }^{[2]}$ The first line of treatment for this disease is usually surgical resection followed by concurrent chemo-radiotherapy. Importantly, the invasive tumor cells that remain after surgery and survive these aggressive treatments are likely responsible for tumor recurrence. Thus, alternative novel therapies that enhance or work in conjunction with conventional treatments are being

\begin{tabular}{|l|l|}
\hline \multicolumn{2}{|c|}{ Access this article online } \\
\hline Quick Response Code: & \\
\hline & Website: \\
\hline & www.nnjournal.net \\
& DOI: \\
& \\
\hline
\end{tabular}

actively pursued. While immunotherapies seemingly provide viable, theoretically effective options, in practice they have produced mixed results. The glioma microenvironment is highly immunosuppressive, thereby inhibiting the efficacy of immune treatments. Microenvironmental factors allow glioma cell evasion from the immune system. The source of the factors is not solely derived from the tumor mass, but rather is also a consequence of chronic inflammation present in the tumor microenvironment.

\section{GLIOMAS AND CHRONIC INFLAMMATION}

Chronic inflammation can influence a wide range of ailments including heart disease, stroke, Crohn's disease, rheumatoid arthritis, multiple sclerosis, asthma, Alzheimer's, depression, fatigue, neuropathic pain, and - relevant to our discussion - cancer. ${ }^{[3-13]}$ Indeed, it is thought that around $15 \%$ of all cancer-related deaths are in some form linked with inflammation as a result of bacterial or viral infections. ${ }^{[14]}$ Further, chronic inflammation occurring within the microenvironment of tumor lesions is now thought to either drive the first malignant-conferring genetic mutations and/or induce them as a result of oncogene expression. ${ }^{[14]}$

Corresponding Author: Carol A. Kruse, Department of Neurosurgery, David Geffen School of Medicine, University of California, Gonda Center, Box 951761, MC 176122, 695 Charles E Young Drive South, Los Angeles, CA 90095, USA. Email: ckruse@mednet.ucla.edu 


\section{GBM TYPES AND STAGES IN DISEASE PROGRESSION}

GBM is classified as one of two types: primary or secondary GBM. Primary GBM arises as the de novo high grade disease that has no discernible stages of progression. Secondary GBM, on the other hand, arises as low grade and over time progresses to a higher-grade of malignancy. Therefore it is extremely difficult - if not impossible - to analyze the changes that arise in a step-wise manner for primary GBM, while the progression of secondary GBM can be closely followed. However, recent genomic analysis of primary resected GBM tissue has allowed for a second dimension of their grouping by gene expression/mutations patterns: neural, pro-neural, classical, and mesenchymal. ${ }^{[15]}$

Contemporary theory links the phenotypic characteristics observed in the tumor microenvironment to each of three stages of glioma pathology: initiation, promotion and progression. ${ }^{[16]} \mathrm{A}$ defect in the switch for wound repair may play a major role in glioma development because it leads to "type 2" chronic inflammation that fails to shut off and this may drive gliomagenesis. Further, "type 2" chronic inflammation, which is propagated indefinitely in the tumor microenvironment, may be critical in triggering tumor initiation. The effect of chronic inflammation that develops in the tumor microenvironment is far reaching beyond the initiating effects, and it may also drive the second stage of disease, glioma promotion. The third and last stage of the disease, glioma progression, is a stage of the disease that loops back adding to the intensity of the underlying inflammation.

\section{The initiating event}

Embracing the cell of origin model, the theoretical consideration of the inflammatory-initiating event beginning with a specific mutation in the cancer stem cell may occur either through oncogene over-expression/stimulation or production of an inflammatory onco-metabolite. A traumatic event at a specific site in the brain may activate all the necessary signal transduction pathways to initiate inflammation. The site of injury could be a source of micro-damage induced by chronic stress, depression, or some other factor extrinsic to the host. ${ }^{[17]}$

As another consideration, the source of the micro-damage and neural-degeneration may be the cancer stem cell itself. Recently, a novel genetic mutation encoding the isocitrate dehydrogenase 1 (IDH1) protein known to be present in a large number of low-grade to secondary GBM tumors has been identified as one of the possible first events in disease initiation. ${ }^{[18]}$ Subsequently, following the identification of this mutated oncogene, its function was revealed. Cells encoding the mutant IDH1 protein were found to convert, in an irreversible reaction, $\alpha$-ketoglutarate to 2-hydroxyglutarate (2-HG). ${ }^{[19]}$ The function of the accumulation of 2-HG and its role in disease progression is not yet fully elucidated. The fundamental role of 2-HG has been difficult to assign partly because its role is unlike conventional onco-metabolites characterized thus far. Rather than promoting disease progression by conferring itself with a proliferative or selective advantage, 2-HG initiates development of the cancer stem cell niche within the frontal lobe. Thus, the onco-metabolite 2-HG is the first example demonstrating that although the derivation of cancer is mono-cellular in nature at initiation, much like tumor promotion and progression, complicated heterogeneous interactions involving multiple cell types occurs. The cellular interplay also offers an explanation to the challenges associated with establishing a tumor model containing solely the IDH1 mutation both in vivo and in vitro. ${ }^{[20]}$ This cancer stem cell niche may in turn provide the mutant IDH1 stem-like cell with the necessary factors to promote self-renewal, further genetic mutations, and ultimately disease progression. Indeed, previous studies in patients suffering from the genetic disorder known as D-2-hydroxyglutaric aciduria, where the accumulation of 2-HG is observed, show ROS-mediated neural excito-toxicity upon NMDA receptor chronic potentiation by 2-HG. ${ }^{[21,22]}$ The neural excito-toxicity fueled by the IDH1 ${ }^{\text {mut }}$ stem-like cell may initiate a neural-inflammatory cycle of wound repair ultimately leading to pro-creation of a cancer stem cell niche that promotes glioma formation and immune evasion. This niche provides the cancer stem cell with growth factors to sustain proliferation and an environment that promotes the emergence of more genetic mutations. Indeed, a connection between excitotoxicity and inflammation has been proposed to be linked by interleukin-1 $\beta .^{[23]}$

\section{Tumor promotion}

Inflammation is the first line of defense in response to tissue injury and/or infection. Pro-inflammatory cytokines such as tumor necrosis factor (TNF)- $\alpha$, Interleukin (IL)-1 $\beta$, and IL-6 are synthesized to initiate the inflammatory cascade. ${ }^{[24]}$ IL-1 has been shown to be a key mediator in the proliferation of "reactive astrocytes". ${ }^{[25]}$ Next, either of two types of inflammatory processes may be activated depending on the stimulus. In the presence of microbial infection or necrotic cell death classical "type 1" inflammation ensues, characterized by the appearance of activated $\mathrm{T}$ helper (Th) 1 lymphocytes. ${ }^{[26]}$ In the presence of parasites, allergens, or phosphatidylserine positive early apoptotic cells the Th2 inflammatory cascade is activated. Interestingly, Th2 inflammation is closely related to wound repair. Indeed, the principal mode of 
action against helminth infection is the "walling off" of large bodies through granuloma formation which bears resemblance to the glial scar encountered in central nervous system (CNS) repair. ${ }^{[27]}$

The initiation of the classical inflammatory response is marked by the localization and subsequent activation of blood circulating monocytes into M1 macrophage. The M1 macrophage are activated by cytokines produced by Th1 cells, like interferon- $\gamma$ (IFN- $\gamma$ ), TNF- $\alpha$, or after recognition of pathogen-associated molecular pattern molecules, through toll-like receptors (TLRs) or C-type lectin receptors. Upon activation, the M1 macrophage promote a proinflammatory environment by releasing cytokines such as TNF- $\alpha$, IL-1, IL-6, IL-12, IFN- $\gamma$, and IL-23. IL-12 stimulates IFN- $\gamma$ production in T lymphocytes and natural killer (NK) cells. ${ }^{[28]}$ Phenotypically, the M1 phenotype is associated with cell mediated cytotoxicity, tissue injury and destruction. Thus, the presence of the M1 macrophage is counter-productive once the invading threat is neutralized and tissue repair is in order. The resolution of the inflammatory response and transition into wound repair is facilitated by the M2 macrophage. One of the key events leading to immunosuppression and activation of "type 2" inflammation is apoptotic cell death of recruited neutrophils. ${ }^{[26]}$ The apoptotic neutrophils signal to close classical inflammation and thus modulate immunosuppression after their engulfment by macrophages. In response, the macrophage upregulate expression of the Th2 anti-inflammatory cytokine IL-10, while significantly downregulating the pro-inflammatory cytokines TNF- $\alpha$, IL-1 $\beta$, and IL-12. ${ }^{[29]}$

Several subtypes of the M2 macrophage exist depending on the inflammatory program that is activated and required. ${ }^{[30]}$ The M2a or alternative macrophage is activated by the cytokines IL-4 and IL-13, and these macrophages are specialized to carry out the allergic response and the killing and encapsulation of parasites. The M2b macrophage is activated by ligation of TLRs + immune complexes and the IL-1 receptor. This macrophage subset is primarily responsible for immune regulation and activation of the Th2 program. The M2c macrophage, activated by the cytokine IL-10, is primarily responsible for matrix deposition and tissue remodeling. Recently, a fourth and distinct subtype, termed the M2d subset, has been identified. This subset is activated by IL-6 and is thought to aid in tumor metastasis and progression. ${ }^{[31]}$ The primary cells responsible for the synthesis of those cytokines are eosinophils, basophils, and CD4 ${ }^{+}$Th2 cells, and tumor cells. ${ }^{[22,33]}$ M2 macrophage down-modulate the release of IL-1, IFN- $\gamma$, IL-12, and TNF- $\alpha .{ }^{[34,35]}$
Also, the recruitment and/or activation of T regulatory lymphocytes are thought to play a key mediating role in the "type 2" inflammatory process. ${ }^{[36-38]}$ Indeed, regulatory $\mathrm{T}$ cells have been found not only to be present in the peripheral circulation of glioma patients in increased percentages compared to controls, but also to infiltrate glioma tissue in a tumor grade-dependent manner. ${ }^{[39,40]}$ Interestingly, some encouraging anti-tumor responses have been obtained in attempts to neutralize the substantial peripheral regulatory $\mathrm{T}$ cell populations encountered in glioma patients with systemic administration of TLR ligands. ${ }^{[41,42]}$ For example, systemic administration of a TLR9 ligand enhanced survival, decreased the number of peripheral regulatory T cells and enhanced the antigen-presenting capacity of infiltrating microglia.

Recently, there have been many studies documenting a decreased risk of glioma development in individuals with asthma, which is also thought to be driven by "type 2" inflammation. ${ }^{[43,44]}$ Reduced immunoglobulin E levels have been found in patients who developed glioma. Further, additional studies have found that specific polymorphisms in genes encoding IL-4RA and IL-13, both factors that induce IgE production in immune cells, are found to be inversely correlated with glioma development. This apparent contradiction can be reconciled by considering the macrophage subtype that predominates in each pathology. The M2a macrophage are induced by IL- 4 and IL-13, express Fc-epsilon receptors, and are involved in the allergic response. On the other hand, the M2b macrophage are induced by engagement of the IL-1 receptor and/or ligation of TLR +/- immune complexes, they express Fc-gamma receptors and are involved in immune regulation. ${ }^{[45,46]}$ It appears that patients developing asthma, as a result of hyperactive IL-13 or IL-4 receptor signaling, are at lower risk of developing gliomas; this may be due to the preferential activation of the M2a subset, which may not be as advantageous to the developing glioma mass that is dominantly populated by the M2b-d macrophage subtypes. IL-10, damage associated molecular pattern molecules, and IL-6 are highly expressed in GBM tissue, where they localize to the macrophage/microglia population. ${ }^{[31,47-51]}$ Further, it has been shown that the presence of IL-4 or IL-13 inhibit the proliferation of astrocytes and low-grade astrocytomas, but not GBM. ${ }^{[52]}$

In glioma tissue, macrophages/microglia can account for up to $30 \%$ of the total lymphocytic infiltrate present in the tumor mass. ${ }^{[53,54]}$ It is now accepted that the macrophage and microglia populations found within glioma originate from distinct progenitor cell populations. Infiltrating macrophages are derived from the bone marrow, whereas microglia are brain-resident; 
they originate from primitive progenitors in the yolk sac and migrate into the CNS during early embryo development (days 8.5 to 9.5). ${ }^{[55,56]}$ It has also been clearly demonstrated, using parabiosis (a technique that surgically connects the circulatory system of two organisms) and experimental auto-immune encephalomyelitis models, that circulating monocytes do not invade the CNS unless the CNS is preconditioned with irradiation or the blood-brain barrier is compromised/damaged. ${ }^{[57-60]}$ Interestingly, a key distinction between "type 1" and "type 2" inflammation is that the latter activates bone-marrow derived macrophage in the CNS and/or brain resident microglia. ${ }^{[61,62]}$ Taken altogether, microglia are probably recruited to the glioma microenvironment at all stages of malignancy, whereas a majority of the macrophages accumulate only after insult or blood-brain barrier breakdown, when chronic "type 2" inflammation is dominant in the glioma microenvironment.

Convertibility of macrophage from an M1 to an M2 polarized state is driven by factors produced by the local glioma microenvironment. Indeed, secreted or displayed glioma factors are capable of manipulating macrophage and microglial behavior that favor tumor survival and growth. Resting microglia are characterized by a ramified morphology; they display extensive branched projections that aid in continuous surveillance of the CNS microenvironment. ${ }^{[63]}$ Glioma cells secrete key immunomodulatory factors that suppress "type 1" immune activity, such as IL-10, IL-4, IL-6, transforming growth factor (TGF)- $\beta$, and prostaglandin E2 ${ }^{[64-66]}$ The cytokines IL-10, IL-4, and IL-6 have been shown to induce an M2 rounded morphology that is typical of activated microglia, whereas the T helper (Th) 3 cytokine, TGF- $\beta$, is known to inhibit microglial cell proliferation and the expression of pro-inflammatory cytokines in vitro. ${ }^{[67]}$ Due to the dominant effect that glioma cells and their secreted factors have on the surrounding cells, it is likely that glioma-recruited microglia preferentially adopt an M2 phenotype. Studies that delineate the interactions between glioma cells and macrophages/microglia are still warranted.

Inflammation status temporally may play a pivotal role in cancer development. The "type 1" pro-inflammatory process cannot be sustained in the absence of proper stimulation. In brain trauma, "type 1" monocyte recruitment from the blood becomes negligible over time, but in low grade gliomas, constant neuronal damage from continuous 2-HG expression may prevent the Th1 inflammatory process from subsiding. Eventually both "type 1" and "type 2" immune responses are both activated leading to chronic inflammation. The strength of "type 2" vs. "type 1" inflammation, which is generally reflected by the serum Th2/Th1 cytokine ratio(s), has been positively correlated with the grade of glioma malignancy ${ }^{[68]}$ As another example, patients displaying genetic polymorphisms of the IL-1, IL-10, and TNF- $\alpha$ genes are at higher risk for developing gastric cancers. ${ }^{[69,70]}$ Studies with human glioma tissues and patient sera indicate Th1, Th2, and Th3 cytokine deregulation as evidenced by increased Th2 associated cytokines such as IL-10 and the Th3 associated cytokine TGF- $\beta$. This increase is offset by a concomitant decrease in Th1 cytokines such as IL-12, IFN- $\gamma$, TNF- $\alpha$, IL-2, and many of their corresponding receptors. ${ }^{[71,72]}$

\section{Tumor progression and invasion}

Cancer cells become "self-sufficient" once they have accumulated the proper genetic mutations to support their own growth. Some of the key findings associated with this stage in disease development include independence from external growth factors, the ability to bypass cell senescence, and dysfunctional apoptotic pathways. In order to develop glioma subtypes, two combinations of genetic mutation may prevail that involve the mutation of the IDH1 gene and p53, resulting in astrocytoma formation, or $1 \mathrm{p} / 19 \mathrm{q}$ loss of heterozygosity $(\mathrm{LOH})$ leading to formation of oligoastrocytomas or oligodendrogliomas. ${ }^{[73]}$ Such mutations increase the proliferative rate of cancer stem cells, which allows them to grow outside of their niche. This concept was confirmed in studies using an IDH1 mutant model both in vitro and in vivo. ${ }^{[74]}$ Tumor samples derived from WHO grade II and III gliomas were successful in retaining the mutation in neurosphere culture. The lower grade gliomas proliferate slowly and are difficult to utilize in standard in vivo xenograft models.

The late stages of "type 2" inflammation primarily consist of extracellular matrix deposition, angiogenesis, and tissue remodeling. Once gliomas becomes "self sufficient", these late stage processes are aberrantly used by the proliferating glioma mass to fuel and sustain proliferation. In particular, myeloid derived suppressors cells are now thought to play a large role in facilitating glioma angiogenesis, neo-vascularization, and invasion [Figure 1] ${ }^{[75]}$ Recent studies have shown that the Tie2-expressing monocyte population is pro-angiogenic, expressing relevant gene transcripts [e.g. matrix metalloproteinase 9, vascular endothelial growth factor (VEGF), cyclooxygenase 2, and wingless-type MMTV integration site family, member 5A] necessary for angiogenesis and neo-vascularization. ${ }^{[76,77]}$ Some myeloid derived suppressor cells also seem to contribute to the integrity of neo-endothelium of tumor vessels because they express endothelial markers, such as CD31 and VEGF receptor and can morphologically resemble endothelial cells. ${ }^{[78]}$ Microglia also localize near the invasive border of the glioma mass at three-fold higher 


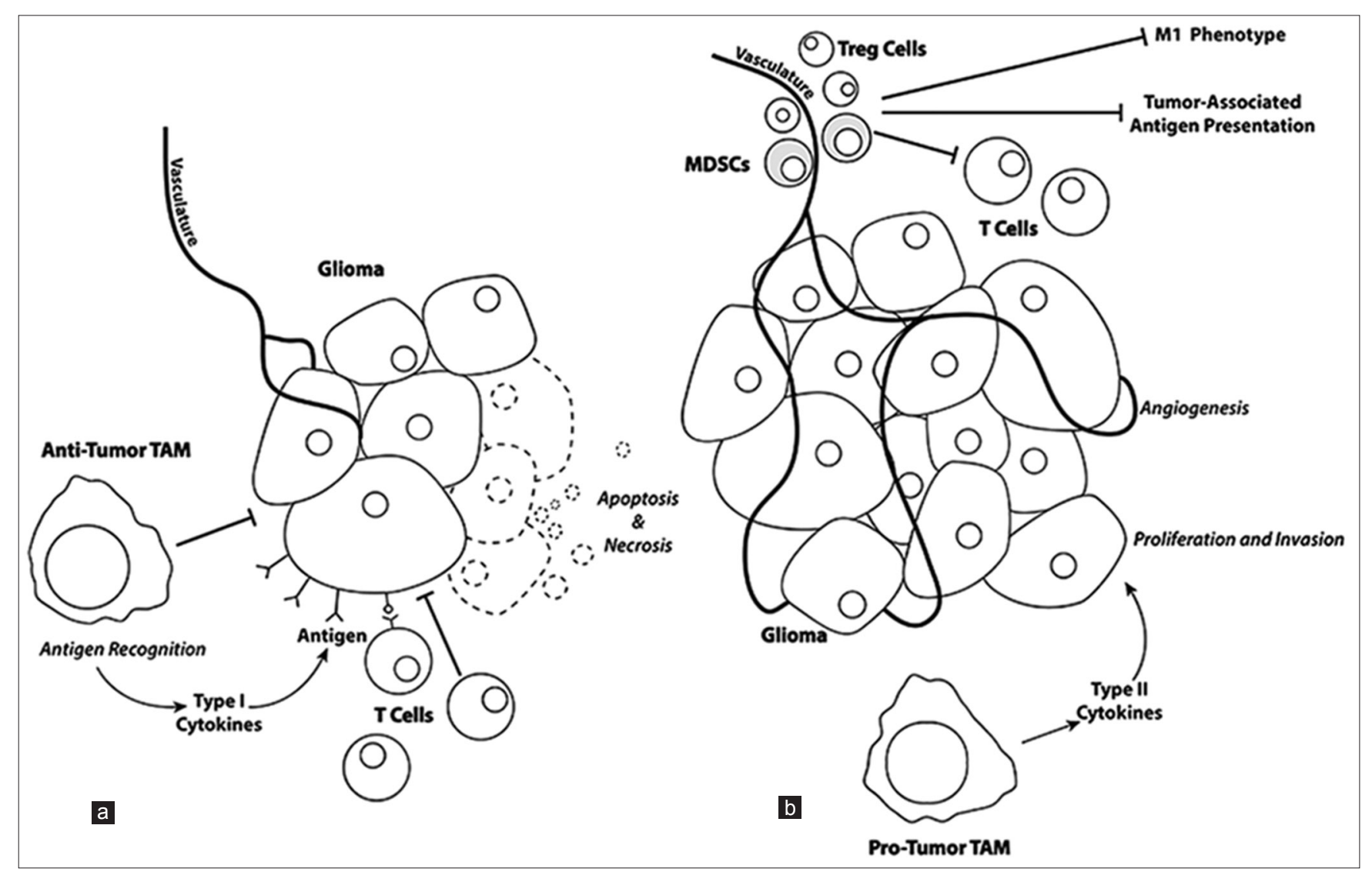

Figure 1: (a) Glioma cell proliferation and invasion is negatively affected when T cells recognize tumor-associated antigens resulting in recognition and tumor cell injury that reduces the tumor mass. (b) Mobilization of T regulatory (Treg) cells and myeloid-derived suppressor cells (MDSCs) to the tumor mass, as well as changes in the phenotypes of tumor-associated macrophages (TAM) result in pro-tumorigenic regulation with increases in tumor cell proliferation, angiogenesis, and invasion

numbers than tumor associated macrophages, suggesting that they might play a key role in glioma invasion. ${ }^{[79]}$

Recent genetic microarray analyses of glioma patient tumors have revealed variations between glioma subtype progression, invasion, and response to therapy. In patients enrolled in a phase I dendritic cell (DC) vaccine therapy clinical trial, we identified significant trends in the mesenchymal glioma subtype, including its progression and its particular responsiveness to treatment. ${ }^{[80]}$ It may be worth exploring if the mesenchymal subgroup of GBM patients have tumor cells carrying LOH in the neurofibromatosis-1 (NF-1) gene, also have NF-1 heterozygous microglia populating the GBM tumor microenvironment. NF-1 heterozygous microglia are essential in driving optic nerve astroglioma with NF-1 LOH. ${ }^{[81]}$ Further, NF-1 heterozygous microglia drive optic nerve glioma by facilitating a relatively more "type 1" chronic inflammatory microenvironment through increased c-Jun- $\mathrm{NH}_{2}$-kinase (JNK) signaling leading to the constitutive expression of higher levels of pro-inflammatory cytokines and proteins TNF- $\alpha$, IL-1, iNOS, and Cox2.$^{[82]}$ The JNK and ERK1/2 pathway is not only responsible for the expression of pro-inflammatory cytokines, but also for the repression of the transcriptional potential of Smad3 activated by TGF- $\beta$ as well. ${ }^{[83-85]}$ Conversely, TGF- $\beta 1$ mediates its effects through inhibition of the ERK pathway. ${ }^{[86]}$ Among its many effects, TGF- $\beta 1$ in the tumor microenvironment is an important regulator of glioma invasion. ${ }^{[87,88]}$ The overactive JNK signaling in NF-1 heterozygous microglia may lead to a constitutively active state of microglia based on morphology and expression profiles. The existence of activated macrophage/microglia within the GBM tumor mass may facilitate a relatively more favorable immunogenic microenvironment that maintains $\mathrm{T}$ cell activation once they are mobilized to tumor by DC vaccination. This theory underscores the crucial role that microglia may play in the tumor microenvironment by potentiating the immune responses against tumor cells. Indeed, it has been proposed that modified microglia may have benefit for glioma treatment. ${ }^{[89,90]}$

Indeed, modulating the microglia in the tumor microenvironment of wild type NF-1 patients may prove to be an important aspect to glioma therapy. IL-10-mediated inhibition of NF- $\mathrm{BB}$ heterodimer (p50/p65) formation leads to an over-expression of the NF-кB homodimer (p50/p50), which prevents transcription elongation of various genes encoding pro-inflammatory cytokines. This is predominantly responsible for the tolerant M2 macrophage phenotype encountered in the microenvironment of wild type NF-1 patients..$^{[91-93]}$ Interestingly, IL-10 is a cytokine translated in tandem with other pro-inflammatory 
cytokines in response to lipopolysaccharide stimuli. ${ }^{[94]}$ This attribute is most likely an evolutionarily hard-wired negative feedback mechanism to preserve the cyclic response curve characteristic in NF- $\kappa \mathrm{B}$ signaling. ${ }^{[95]}$ We propose that the presence of IL-10 in the glioma microenvironment substantially dampens the transient pro-inflammatory activating pulse delivered by tumor-lysate activated DCs and booster injection of TLR agonist. This mechanism is circumvented in NF-1 heterozygous microglia through deregulated Ras/Rac1/ JNK/C-Jun/AP-1 signaling, which operates in parallel and independent of the NF- $\kappa$ B signaling pathway [Figure 2]. Deactivating antibodies against IL-10 may restore the formation of the NF- $\mathrm{BB}$ heterodimer ultimately leading to a M1 microglia phenotype without overshooting the pro-inflammatory response, which may have detrimental effects on patients. Then, effectors cells mobilized by the vaccine can operate and maintain functionality by encountering a skewed microenvironment to a "type 1 " pro-inflammatory state. Ultimately tumor regression may lead to a natural resolution of the inflammatory phase mediated in large part by IL-10.

\section{IMMUNE AND GENE THERAPEUTICS THAT ENGENDER INFLAMMATION}

Our translational immunotherapy research team has a long-standing interest in the development of novel therapeutic options for brain tumor patients. Our group and others have preclinically explored active and passive immune and gene therapy approaches, some of which are translated to the clinic. ${ }^{[96,97]}$ The therapies are generally designed as adjuvant treatments and entail tumor resection followed by administration

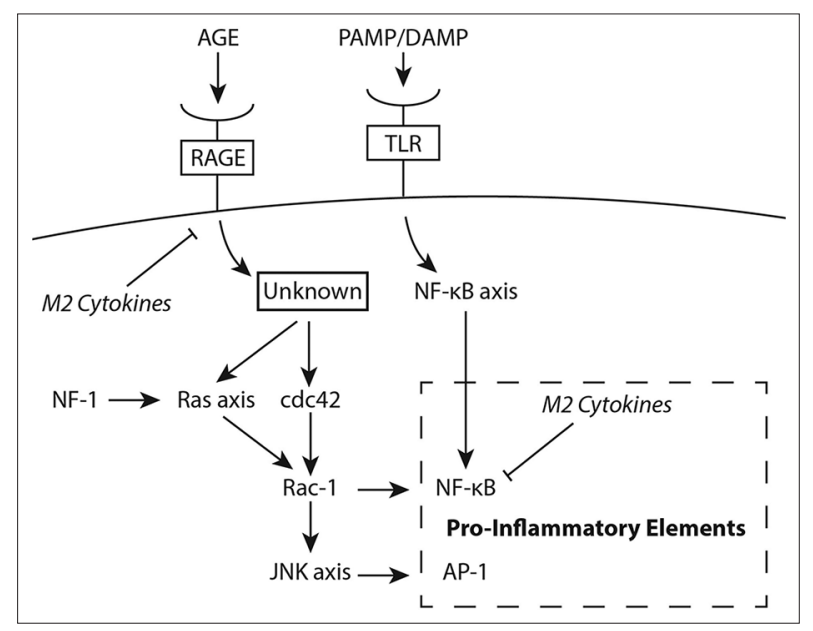

Figure 2: Signaling imparted through interactions of advanced glycation end products (AGE) with the receptors for AGE (RAGE) versus interactions of pathogen associated molecular pattern (PAMP) or damage associated molecular pattern (DAMP) molecules with Toll like receptors (TLR). The schematic shows the two signaling pathways that operate in parallel but independent to each other; both lead to expression of pro-inflammatory cytokines. The presence of anti-inflammatory (M2) cytokines inhibits the expression of pro-inflammatory cytokines of both inflammatory response pathways. NF: Neurofibromatosis; JNK: Jun-NH2-kinase of the experimental agent. Surgical resection serves multiple purposes. Importantly, resection reduces tumor burden and the immunosuppressive factors present in the tumor microenvironment that will enhance the effectiveness of the immunotherapy. Also, the degree of the mobilized inflammatory response is minimized. The tumor specimens are valuable since they serve as a source of tumor associated antigens to make vaccines. Likewise, tumor specimens can be processed and placed into culture where the cells can serve in in vitro studies and as target cells for cytotoxicity testing. ${ }^{[98]}$

We have successfully used tumor-lysate pulsed DC vaccines that are given with or without TLR agonist; they represent an active immunotherapy strategy designed to enhance cell-mediated immunity. ${ }^{[99]}$ The conclusion of a phase II clinical trial has shown the vaccine treatment to extend median survival to 34 months. It appears that the treatment has a relevant role in flagging the tumor cells remaining after surgical resection. ${ }^{[100]}$ We have also examined a passive immunotherapy approach that utilizes effector alloreactive cytotoxic T lymphocytes (alloCTL) that are intratumorally implanted with low doses of Interleukin-2. ${ }^{[101]}$ The allogeneic CTL are trained in vitro to target patient human leukocyte antigens that are present on glioma cells but not on normal neuroglia. A pilot clinical study described at www.clinicaltrials. gov (NCT00068510), ${ }^{[102,103]}$ suggested a clinical response in recurrent WHO grade III gliomas. These studies led to a second phase I dose escalation trial that is currently open for patient enrollment at University of California, Los Angeles (www.clinicaltrials.gov; NCT01144247).

In another gene therapy approach, transduction of glioma cells with retroviral replicating vectors (RRV) coding for pro-drug activating enzymes followed by their exposure to non-toxic pro-drug has also proven to be another potent cancer therapy strategy. Non-cytolytic RRV are particularly well suited for the treatment of primary or metastatic brain tumors. In the CNS, normal brain neuroglial cells are relatively quiescent, thus, the dividing glioma cells are selectively targeted by the RRV. After achieving genomic integration, the viral constructs can stably seed the tumor mass and replicate within the tumor cells even as they infiltrate in vivo. Pro-drug administration results in targeted destruction of the cells harboring the RRV. Such an approach utilizes RRV coding for yeast cytosine deaminase. Upon administration of the pro-drug, 5 -fluorocytosine, the drug is converted to its toxic form, 5-fluorouracil. If sufficient time is allowed for RRV spreading, the administered prodrug converts to a cytotoxic form, killing infected cells and providing tumor cytoreduction. Predicated upon successful and extensive preclinical testing, ${ }^{[104-108]}$ phase I clinical trials 
are testing the RRV suicide gene therapy in recurrent glioma patients (www.clinicaltrials.gov, NCT01156584; NCT01470794; NCT01985256).

Most recently, our attention has turned to preclinical studies examining a more aggressive combined immunogene therapy approach. RRV-transduced alloCTL have effector and delivery functions. If combined with pro-drug administration, the immunogene therapy is more efficacious in vivo than the individual therapies and control groups. Better extension was obtained in the survival of mice bearing orthotopic intracranial implants of breast carcinoma. ${ }^{[109,110]}$ The immunogene therapy is similarly being tested in a syngeneic mouse glioma model. If the data look as promising in this model after optimizing doses and timing, combining the therapies should be easily translatable since both are being individually tested now in the clinic.

\section{Challenges in immunotherapy}

Immunotherapeutics do not always robustly provide efficacious treatment for gliomas. This may be due to the concurrent activation of both pro- and anti-inflammatory responses and this may have clinical and therapeutic consequences [Figure 3]. Clinically, immunotherapy entails protracted treatments. While manageable in theory, maintaining patients on immune treatments over the extended period necessary to effect a cell-mediated immune response has proven difficult. ${ }^{[102]}$ Furthermore, inflammation associated with immune therapy is indistinguishable from tumor progression on follow-up magnetic resonance images; a clinician must give benefit of doubt and recommend other treatments inhibiting possible tumor growth. The immunotherapy is unfortunately either interrupted or incompletely tested. With the inability to distinguish pseudo- from tumor- progression, completion of trials is difficult, especially with the availability of drugs such as Avastin, Temodar, or other chemo- or radio-therapeutics for use at recurrence. Developing an appropriate set of neuroimaging parameters to distinguish inflammation from tumor growth would help advance this field.
Perhaps one solution would be to offer immunotherapy upfront, or integrate it with standard of care treatments.

Therapeutically, the chronic inflammation that develops and worsens in correlation with glioma grade promotes a skewed "type 2" inflammatory state, both in the local tumor microenvironment and systemically. ${ }^{[40]}$ Once gliomas are in the progression phase (i.e. pro-wound repair) deactivation of T cell-mediated immune response occurs. To effectively mount a host-generated, anti-tumor response immune homeostasis must be "reset" and skewed towards a "type 1" inflammatory state. An interesting possibility to generate a (Type 1) inflammatory response is the administration of attenuated microbes. Indeed, Bacillus Calmette Guérin (BCG) is effectively used for immunotherapy of superficial bladder cancer. ${ }^{[11]}$ The success of BCG as a therapeutic modality for low-grade bladder cancer can be effectively attributed to two characteristics: immunogenicity and anti-tumor targeting. In BCG tumor models, the initial presence of both Th1 and Th2 inflammatory cytokines was also observed, but then later skewed towards Th1 cytokines that in particular involved the up-regulation of IFN- $\gamma \cdot{ }^{[112]}$ However, the situation is complicated for the treatment of high-grade glioma. Studies of immunosuppression have shown that once "type 2" inflammation has been activated, challenge with a bacterial lipopolysaccharides fails to skew the cytokine expression towards "type 1" in a time-dependent manner. ${ }^{[29]}$ Thrombospondin receptor (CD36) expressed on macrophages among other cell types formed a "molecular bridge" between anionic sites on apoptotic cells and CD36. This cell-cell signaling interaction was sufficient to signal the resolution of inflammation and activation of "type 2" inflammation. Further, antibodies against thrombospondin prevented its binding to CD36 receptor leading to a decrease of IL-10 and restored TNF- $\alpha$, IL-1 $\beta$, and IL-12 in the presence of apoptotic cells. Thus, it appears that immune homeostasis must first be restored for high-grade tumors that are driven by "type 2" inflammation before further intervention
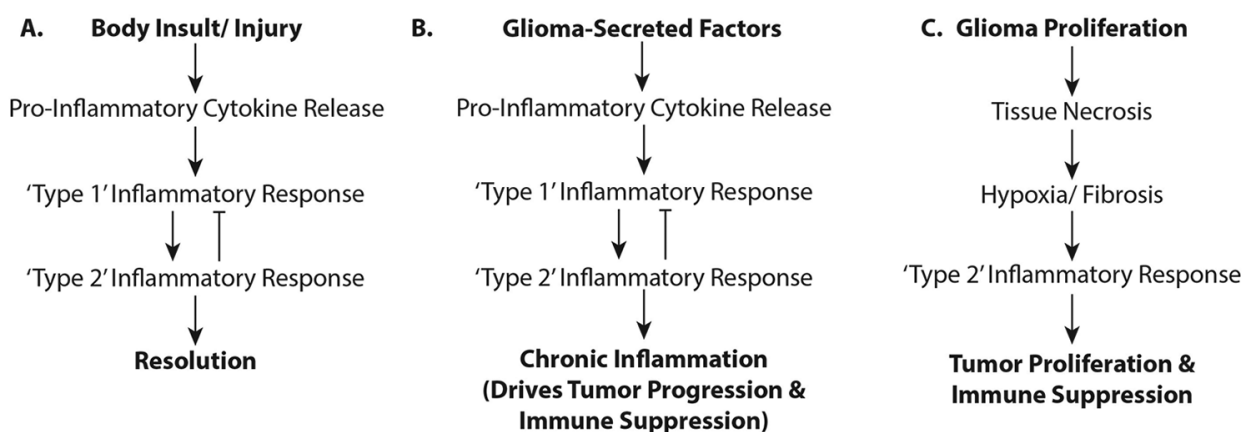

Figure 3: Activation of pro- and anti-inflammatory responses in glioma patients. The flowcharts illustrate (a) the "normal" physiologic processes in the inflammatory response and its resolution; (b) the physiologic processes occurring when glioma-secreted factors influence a state of chronic inflammation resulting in glioma progression; and (c) how rapid glioma growth creates a necrotic/hypoxic environment supporting tumor proliferation and immunosuppression 
to activate the "type 1" inflammatory response can be implemented. Enhancing the endogenous immune response by deactivating the ensuing chronic inflammatory tumor microenvironment might provoke an immune response potent enough to activate and mobilize endogenous CTL and NK cells to eliminate the threat posed by high-grade cancerous masses.

\section{CONCLUSION}

It has long been held that tumor cells outwit the host's defenses by altering their own cellular signaling pathways. The pathway exploited to achieve malignancy may be a combination of unique derivations. Gliomas are known to exhibit compensatory activity in that when supplied with selective pressure from one treatment, they readily adapt with other mutations to survive. Other mounting evidence now suggests that some of the pathways exploited by cancer cells adopt a more malignant phenotype and are simply responses to the stimuli created by the rapidly dividing tumor cells rather than novel re-circuited pathways exploited by neoplastic cells for growth. One of the crucial responses facilitating and nurturing cancerous transformation is inflammation. A chronically active inflammatory microenvironment provides the developing cancerous mass with proliferative and mutational factors necessary to realize "self-sufficiency". It is evident that some tumors can bypass this "nurturing stage" as might be expected with primary GBM. Regardless, once this "self-sufficiency" is realized, the tumor is able to survive outside of the cancer stem cell niche. Empowered with constant proliferative cues the tumor mass divides uncontrolled. The increased proliferation results in necrosis and the resultant environment is skewed more strongly towards the Th2 inflammatory response. Thus, for high-grade gliomas a higher Th2/Th1 cytokine ratio supports the production of other immunosuppressive factors. To mount a successful cytotoxic anti-tumor response, it is crucial to restore a balanced Th2/Th1 cytokine ratio of 1:1 or less. This should decrease the proliferative rate of the tumor mass as well, since it is the Th2 response that ultimately works with the tumor cell to drive the angiogenic response. Ultimately, successful brain tumor immunotherapy should leave patients with intact immunosurveillance function and the ability to enact a cell-mediated response in the event of recurrence.

\section{ACKNOWLEDGMENTS}

Supported in part by NIH R01CA125244 (Kruse CA, Liau LM), R01CA154256 (Kruse CA), R01 CA121258 (Kasahara N, Kruse CA), the Joan S. Holmes Memorial Research Fund (Kruse CA), NIH/NCATS UCLA CTSI Grant Number UL1TR000124 (Liau LM), a NIH Minority Supplement
Award to NIH R01CA125244 (Soto H), a UCLA Scholars in Translational Medicine Program Award (Yang I), and the STOP CANCER Jason Dessel Memorial Seed Grant (Yang I).

\section{REFERENCES}

1. Ostrom QT, Gittleman H, Farah P, Ondracek A, Chen Y, Wolinsky Y, Stroup NE, Kruchko C, Barnholtz-Sloan JS. CBTRUS statistical report: Primary brain and central nervous system tumors diagnosed in the United States in 2006-2010. Neuro Oncol 2013;15 Suppl 2:ii1-56.

2. Stupp R, Mason WP, van den Bent MJ, Weller M, Fisher B, Taphoorn MJ, Belanger K, Brandes AA, Marosi C, Bogdahn U, Curschmann J, Janzer RC, Ludwin SK, Gorlia T, Allgeier A, Lacombe D, Cairncross JG, Eisenhauer E, Mirimanoff RO; European Organisation for Research and Treatment of Cancer Brain Tumor and Radiotherapy Groups; National Cancer Institute of Canada Clinical Trials Group. Radiotherapy plus concomitant and adjuvant temozolomide for glioblastoma. $N$ Engl $J$ Med 2005;352:987-96.

3. Hansson GK. Inflammation, atherosclerosis, and coronary artery disease. N Engl J Med 2005;352:1685-95.

4. Lindsberg PJ, Grau AJ. Inflammation and infections as risk factors for ischemic stroke. Stroke 2003;34:2518-32.

5. Sartor RB. Mechanisms of disease: pathogenesis of Crohn's disease and ulcerative colitis. Nat Clin Pract Gastroenterol Hepatol 2006;3:390-407.

6. McInnes IB, Schett G. Cytokines in the pathogenesis of rheumatoid arthritis. Nat Rev Immunol 2007;7:429-42.

7. Peterson JW, Bo L, Mork S, Chang A, Trapp BD. Transected neurites, apoptotic neurons, and reduced inflammation in cortical multiple sclerosis lesions. Ann Neurol 2001;50:389-400.

8. Bousquet J, Chanez P, Lacoste JY, Barnéon G, Ghavanian N, Enander I, Venge P, Ahlstedt S, Simony-Lafontaine J, Godard P, Michel FB. Eosinophilic inflammation in asthma. $N$ Engl $J$ Med 1990;323:1033-9.

9. Akiyama H, Barger S, Barnum S, Bradt B, Bauer J, Cole GM, Cooper NR, Eikelenboom P, Emmerling M, Fiebich BL, Finch CE, Frautschy S, Griffin WS, Hampel H, Hull M, Landreth G, Lue L, Mrak R, Mackenzie IR, McGeer PL, O'Banion MK, Pachter J, Pasinetti G, Plata-Salaman C, Rogers J, Rydel R, Shen Y, Streit W, Strohmeyer R, Tooyoma I, Van Muiswinkel FL, Veerhuis R, Walker D, Webster S, Wegrzyniak B, Wenk G, Wyss-Coray T. Inflammation and alzheimer's disease. Neurobiol Aging 2000;21:383-421.

10. Dantzer R. Depression and inflammation: an intricate relationship. Biol Psychiatry 2012;71:4-5.

11. Schubert C, Hong S, Natarajan L, Mills PJ, Dimsdale JE. The association between fatigue and inflammatory marker levels in cancer patients: a quantitative review. Brain Behav Immun 2007;21:413-27.

12. Moalem G, Tracey DJ. Immune and inflammatory mechanisms in neuropathic pain. Brain Res Rev 2006;51:240-64.

13. Balkwill F, Mantovani A. Inflammation and cancer: back to Virchow? Lancet 2001;357:539-45.

14. Mantovani A, Allavena P, Sica A, Balkwill F. Cancer-related inflammation. Nature 2008;454:436-44.

15. Verhaak RG, Hoadley KA, Purdom E, Wang V, Qi Y, Wilkerson MD Miller CR, Ding L, Golub T, Mesirov JP, Alexe G, Lawrence M, O'Kelly M, Tamayo P, Weir BA, Gabriel S, Winckler W, Gupta S, Jakkula L, Feiler HS, Hodgson JG, James CD, Sarkaria JN, Brennan C, Kahn A, Spellman PT, Wilson RK, Speed TP, Gray JW, Meyerson M, Getz G, Perou CM, Hayes DN; Cancer Genome Atlas Research Network. Integrated genomic analysis identifies clinically relevant subtypes of glioblastoma characterized by abnormalities in PDGFRA, IDH1, EGFR, and NF1. Cancer Cell 2010;17:98-110.

16. Philip M, Rowley DA, Schreiber H. Inflammation as a tumor promoter in cancer induction. Semin Cancer Biol 2004;14:433-9.

17. Wager-Smith K, Markou A. Depression: A repair response to 
stress-induced neuronal microdamage that can grade into a chronic neuroinflammatory condition? Neurosci Biobehavioral Rev 2011;35:742-64.

18. Watanabe T, Nobusawa S, Kleihues P, Ohgaki H. IDH1 mutations are early events in the development of astrocytomas and oligodendrogliomas. Am J Pathol 2009;174:1149-53.

19. Dang L, White DW, Gross S, Bennett BD, Bittinger MA, Driggers EM, Fantin VR, Jang HG, Jin S, Keenan C, Marks KM, Prins RM, Ward PS, Yen KE, Liau LM, Rabinowitz JD, Cantley LC, Thompson CB, Vander Heiden MG, Su SM. Cancer-associated IDH1 mutations produce 2-hydroxyglutarate. Nature 2010;465:966.

20. Piaskowski S, Bienkowski M, Stoczynska-Fidelus E, Stawski R, Sieruta M, Szybka M, Papierz W, Wolanczyk M, Jaskolski DJ, Liberski PP, Rieske P. Glioma cells showing IDH1 mutation cannot be propagated in standard cell culture conditions. $\mathrm{Br} J$ Cancer 2011;104:968-70

21. Kölker S, Pawlak V, Ahlemeyer B, Okun JG, Hörster F, Mayatepek E, Krieglstein J, Hoffmann GF, Köhr G. NMDA receptor activation and respiratory chain complex $\mathrm{V}$ inhibition contribute to neurodegeneration in d-2-hydroxyglutaric aciduria. Eur J Neurosci 2002;16:21-8

22. Guemez-Gamboa A, Estrada-Sanchez AM, Montiel T, Páramo B, Massieu L, Morán J. Activation of NOX2 by the stimulation of ionotropic and metabotropic glutamate receptors contributes to glutamate neurotoxicity in vivo through the production of reactive oxygen species and calpain activation. $J$ Neuropathol Exp Neurol 2011;70:1020-35

23. Fogal B, Hewett SJ. Interleukin-1beta: a bridge between inflammation and excitotoxicity? J Neurochem 2008;106:1-23.

24. Tracey KJ, Cerami A. Tumor necrosis factor, other cytokines and disease. Ann Rev Cell Biol 1993;9:317-43

25. Woiciechowsky C, Schoning B, Stoltenburg-Didinger G, Stockhammer F, Volk HD. Brain-IL-1 beta triggers astrogliosis through induction of IL-6: inhibition by propranolol and IL-10. Med Sci Monit 2004;10:BR325-30.

26. Soehnlein O, Lindbom L. Phagocyte partnership during the onset and resolution of inflammation. Nat Rev Immunol 2010;10:427-39.

27. Allen JE, Wynn TA. Evolution of Th2 immunity: a rapid repair response to tissue destructive pathogens. PLoS Pathog 2011; 7:e1002003.

28. D'Andrea A, Rengaraju M, Valiante NM, Chehimi J, Kubin M, Aste M, Chan SH, Kobayashi M, Young D, Nickbarg E. Production of natural killer cell stimulatory factor (interleukin 12) by peripheral blood mononuclear cells. J Exp Med 1992;176:1387-98.

29. Voll RE, Herrmann M, Roth EA, Stach C, Kalden JR, Girkontaite I. Immunosuppressive effects of apoptotic cells. Nature 1997;390:350-1.

30. Mantovani A, Sica A, Sozzani S, Allavena P, Vecchi A, Locati M. The chemokine system in diverse forms of macrophage activation and polarization. Trends Immunol 2004;25:677-86

31. Duluc D, Delneste Y, Tan F, Moles MP, Grimaud L, Lenoir J, Preisser L, Anegon I, Catala L, Ifrah N, Descamps P, Gamelin E, Gascan H, Hebbar M, Jeannin P. Tumor-associated leukemia inhibitory factor and IL-6 skew monocyte differentiation into tumor-associated macrophage-like cells. Blood 2007;110:4319-30.

32. Voehringer D, Shinkai K, Locksley RM. Type 2 immunity reflects orchestrated recruitment of cells committed to IL-4 production. Immunity 2004;20:267-77.

33. Anthony RM, Rutitzky LI, Urban JF Jr, Stadecker MJ, Gause WC. Protective immune mechanisms in helminth infection. Nat Rev Immunol 2007;7:975-87.

34. de Waal Malefyt R, Abrams J, Bennett B, Figdor CG, de Vries JE. Interleukin 10(IL-10) inhibits cytokine synthesis by human monocytes: an autoregulatory role of IL-10 produced by monocytes. J Exp Med 1991;174:1209-20.

35. D'Andrea A, Aste-Amezaga M, Valiante NM, Ma X, Kubin M, Trinchieri G. Interleukin 10 (IL-10) inhibits human lymphocyte interferon gamma-production by suppressing natural killer cell stimulatory factor/IL-12 synthesis in accessory cells. $J$ Exp Med $1993 ; 178: 1041-8$
36. Maizels RM, Yazdanbakhsh M. Immune regulation by helminth parasites: cellular and molecular mechanisms. Nat Rev Immunol 2003;3:733-44

37. Humphries W, Wei J, Sampson JH, Heimberger AB. The role of tregs in glioma-mediated immunosuppression: potential target for intervention. Neurosurg Clin N Am 2010;21:125-37.

38. Sonabend AM, Rolle CE, Lesniak MS. The role of regulatory T cells in malignant glioma. Anticancer Res 2008;28:1143-50.

39. El Andaloussi A, Lesniak MS. An increase in CD4+CD25+FOXP3+regulatory $\mathrm{T}$ cells in tumor-infiltrating lymphocytes of human glioblastoma multiforme. Neuro Oncol 2006;8:234-43.

40. Fecci PE, Mitchell DA, Whitesides JF, Xie W, Friedman AH, Archer GE, Herndon JE, Bigner DD, Dranoff G, Sampson JH. Increased regulatory $\mathrm{T}$-cell fraction amidst a diminished $\mathrm{CD} 4$ compartment explains cellular immune defects in patients with malignant glioma. Cancer Res 2006;66:3294-302.

41. El Andaloussi A, Sonabend AM, Han Y, Lesniak MS. Stimulation of TLR9 with CpG ODN enhances apoptosis of glioma and prolongs the survival of mice with experimental brain tumors. Glia 2006;54:526-35.

42. Peng G, Guo Z, Kiniwa Y, Voo KS, Peng W, Fu T, Wang DY, Li Y, Wang HY, Wang RF. Toll-like receptor 8-mediated reversal of CD4+regulatory T cell function. Science 2005;309:1380-4.

43. Schwartzbaum J, Ahlbom A, Malmer B, Lonn S, Brookes AJ, Doss H, Debinski W, Henriksson R, Feychting M. Polymorphisms associated with asthma are inversely related to glioblastoma multiforme. Cancer Res 2005;65:6459-65.

44. Wiemels JL, Wiencke JK, Patoka J, Moghadassi M, Chew T, McMillan A, Miike R, Barger G, Wrensch M. Reduced immunoglobulin E and allergy among adults with glioma compared with controls. Cancer Res 2004;64:8468-73.

45. Leidi M, Gotti E, Bologna L, Miranda E, Rimoldi M, Sica A, Roncalli M, Palumbo GA, Introna M, Golay J. M2 macrophages phagocytose rituximab-opsonized leukemic targets more efficiently than $\mathrm{m} 1$ cells in vitro. $J$ Immunol 2009;182:4415-22.

46. te Velde AA, de Waal Malefijt R, Huijbens RJ, de Vries JE, Figdor CG IL-10 stimulates monocyte Fc gamma $\mathrm{R}$ surface expression and cytotoxic activity. Distinct regulation of antibody-dependent cellular cytotoxicity by IFN-gamma, IL-4, and IL-10. J Immunol 1992;149:4048-52

47. Huettner C, Czub S, Kerkau S, Roggendorf W, Tonn JC. Interleukin 10 is expressed in human gliomas in vivo and increases glioma cell proliferation and motility in vitro. Anticancer Res 1997;17:3217-24.

48. Huettner C, Paulus W, Roggendorf W. Messenger RNA expression of the immunosuppressive cytokine IL-10 in human gliomas. Am J Pathol 1995; 146:317-22.

49. Lisi L, Stigliano E, Lauriola L, Navarra P, Dello Russo C. Proinflammatory-activated glioma cells induce a switch in microglial polarization and activation status, from a predominant $\mathrm{M} 2 \mathrm{~b}$ phenotype to a mixture of $\mathrm{M} 1$ and $\mathrm{M} 2 \mathrm{a} / \mathrm{B}$ polarized cells. ASN Neuro 2014; 6:e00144.

50. Samaras V, Piperi C, Korkolopoulou P, Zisakis A, Levidou G, Themistocleous MS, Boviatsis EI, Sakas DE, Lea RW, Kalofoutis A, Patsouris E. Application of the ELISPOT method for comparative analysis of interleukin (IL)-6 and IL-10 secretion in peripheral blood of patients with astroglial tumors. Mol Cell Biochem 2007;304:343-51.

51. Wagner S, Czub S, Greif M, Vince GH, Suss N, Kerkau S, Rieckmann P, Roggendorf W, Roosen K, Tonn JC. Microglial/ macrophage expression of interleukin 10 in human glioblastomas. Int J Cancer 1999;82:12-6.

52. Liu H, Jacobs BS, Liu J, Prayson RA, Estes ML, Barnett GH, Barna BP. Interleukin-13 sensitivity and receptor phenotypes of human glial cell lines: non-neoplastic glia and low-grade astrocytoma differ from malignant glioma. Cancer Immunol Immunother 2000;49:319-24.

53. Badie B, Schartner JM. Flow cytometric characterization of tumor-associated macrophages in experimental gliomas. 
Neurosurgery 2000;46:957-61; discussion 961-2.

54. da Fonseca AC, Badie B. Microglia and macrophages in malignant gliomas: recent discoveries and implications for promising therapies. Clin Developmental Immunol 2013;2013:264124.

55. Saijo K, Glass CK. Microglial cell origin and phenotypes in health and disease. Nat Rev Immunol 2011;11:775-87.

56. Ginhoux F, Greter M, Leboeuf M, Nandi S, See P, Gokhan S, Mehler MF, Conway SJ, Ng LG, Stanley ER, Samokhvalov IM, Merad M. Fate mapping analysis reveals that adult microglia derive from primitive macrophages. Science 2010;330:841-5.

57. King IL, Dickendesher TL, Segal BM. Circulating Ly-6C+myeloid precursors migrate to the $\mathrm{CNS}$ and play a pathogenic role during autoimmune demyelinating disease. Blood 2009;113:3190-7.

58. Mildner A, Mack M, Schmidt H, Bruck W, Djukic M, Zabel MD, Hille A, Priller J, Prinz M. CCR2 + Ly-6Chi monocytes are crucial for the effector phase of autoimmunity in the central nervous system. Brain 2009;132:2487-500.

59. Mildner A, Schlevogt B, Kierdorf K, Bottcher C, Erny D, Kummer MP, Quinn M, Brück W, Bechmann I, Heneka MT, Priller J, Prinz M. Distinct and non-redundant roles of microglia and myeloid subsets in mouse models of Alzheimer's disease. $J$ Neurosci 2011;31:11159-71.

60. Ransohoff RM. Microgliosis: the questions shape the answers. Nat Neurosci 2007;10:1507-9.

61. Jenkins SJ, Ruckerl D, Cook PC, Jones LH, Finkelman FD, van Rooijen N, MacDonald AS, Allen JE. Local macrophage proliferation, rather than recruitment from the blood, is a signature of TH2 inflammation. Science 2011;332:1284-8.

62. Gibson RM, Rothwell NJ, Le Feuvre RA. CNS injury: the role of the cytokine IL-1. Vet $J$ 2004;168:230-7.

63. Nimmerjahn A, Kirchhoff F, Helmchen F. Resting microglial cells are highly dynamic surveillants of brain parenchyma in vivo. Science 2005;308:1314-8

64. Charles NA, Holland EC, Gilbertson R, Glass R, Kettenmann H. The brain tumor microenvironment. Glia 2011;59:1169-80.

65. Ghosh A, Chaudhuri S. Microglial action in glioma: a boon turns bane. Immunol Lett 2010;131:3-9.

66. Qiu B, Zhang D, Wang C, Tao J, Tie X, Qiao Y, Xu K, Wang Y, Wu A. IL-10 and TGF-beta2 are overexpressed in tumor spheres cultured from human gliomas. Mol Biol Rep 2011;38:3585-91.

67. Wu A, Wei J, Kong LY, Wang Y, Priebe W, Qiao W, Sawaya R, Heimberger AB. Glioma cancer stem cells induce immunosuppressive macrophages/microglia. Neuro Oncol 2010;12:1113-25.

68. Gousias K, Markou M, Arzoglou V, Voulgaris S, Vartholomatos G, Kostoula A, Voulgari P, Polyzoidis K, Kyritsis AP. Frequent abnormalities of the immune system in gliomas and correlation with the WHO grading system of malignancy. $J$ Neuroimmunol 2010;226:136-42

69. El-Omar EM, Carrington M, Chow WH, McColl KE, Bream JH, Young HA, Herrera J, Lissowska J, Yuan CC, Rothman N, Lanyon G, Martin M, Fraumeni JF Jr, Rabkin CS. Interleukin-1 polymorphisms associated with increased risk of gastric cancer. Nature 2000;404:398-402.

70. El-Omar EM, Rabkin CS, Gammon MD, Vaughan TL, Risch HA, Schoenberg JB, Stanford JL, Mayne ST, Goedert J, Blot WJ, Fraumeni JF Jr, Chow WH. Increased risk of noncardia gastric cancer associated with proinflammatory cytokine gene polymorphisms. Gastroenterology 2003;124:1193-201.

71. Kumar R, Kamdar D, Madden L, Hills C, Crooks D, O'Brien D, Greenman J. Th1/Th2 cytokine imbalance in meningioma, anaplastic astrocytoma and glioblastoma multiforme patients. Oncol Rep 2006;15:1513-6.

72. Hao C, Parney IF, Roa WH, Turner J, Petruk KC, Ramsay DA. Cytokine and cytokine receptor mRNA expression in human glioblastomas: evidence of Th1, Th2 and Th3 cytokine dysregulation. Acta Neuropathol 2002;103:171-8.

73. Lai A, Kharbanda S, Pope WB, Tran A, Solis OE, Peale F, Forrest WF, Pujara K, Carrillo JA, Pandita A, Ellingson BM, Bowers CW, Soriano RH, Schmidt NO, Mohan S, Yong WH,
Seshagiri S, Modrusan Z, Jiang Z, Aldape KD, Mischel PS, Liau LM, Escovedo CJ, Chen W, Nghiemphu PL, James CD, Prados MD, Westphal M, Lamszus K, Cloughesy T, Phillips HS. Evidence for sequenced molecular evolution of IDH1 mutant glioblastoma from a distinct cell of origin. J Clin Oncol 2011;29:4482-90.

74. Luchman HA, Stechishin OD, Dang NH, Blough MD, Chesnelong C, Kelly JJ, Nguyen SA, Chan JA, Weljie AM, Cairncross JG, Weiss S. An in vivo patient-derived model of endogenous IDH1-mutant glioma. Neuro Oncol 2012;14:184-91.

75. Kushchayev SV, Kushchayeva YS, Wiener PC, Badie B, Preul MC Monocyte-Derived Cells of the Brain and Malignant Gliomas: The Double Face of Janus. World Neurosurg 2012; Epub ahead of print

76. Coffelt SB, Tal AO, Scholz A, De Palma M, Patel S, Urbich C, Biswas SK, Murdoch C, Plate KH, Reiss Y, Lewis CE. Angiopoietin-2 regulates gene expression in TIE2-expressing monocytes and augments their inherent proangiogenic functions. Cancer Res 2010;70:5270-80.

77. De Palma M, Venneri MA, Galli R, Sergi Sergi L, Politi LS, Sampaolesi M, Naldini L. Tie2 identifies a hematopoietic lineage of proangiogenic monocytes required for tumor vessel formation and a mesenchymal population of pericyte progenitors. Cancer Cell 2005;8:211-26

78. Gabrilovich D. Mechanisms and functional significance of tumour-induced dendritic-cell defects. Nat Rev Immunol 2004;4:941-52.

79. Watters JJ, Schartner JM, Badie B. Microglia function in brain tumors. J Neurosci Res 2005;81:447-55.

80. Prins RM, Soto H, Konkankit V, Odesa SK, Eskin A, Yong WH, Nelson SF, Liau LM. Gene expression profile correlates with T-cell infiltration and relative survival in glioblastoma patients vaccinated with dendritic cell immunotherapy. Clin Cancer Res 2011;17:1603-15.

81. Bajenaru ML, Hernandez MR, Perry A, Zhu Y, Parada LF Garbow JR, Gutmann DH. Optic nerve glioma in mice requires astrocyte Nf1 gene inactivation and Nf1 brain heterozygosity. Cancer Res 2003;63:8573-7.

82. Daginakatte GC, Gianino SM, Zhao NW, Parsadanian AS, Gutmann DH. Increased c-Jun-NH2-kinase signaling in neurofibromatosis-1 heterozygous microglia drives microglia activation and promotes optic glioma proliferation. Cancer Res 2008;68:10358-66

83. Liu D, Yumoto H, Hirota K, Murakami K, Takahashi K, Hirao K, Matsuo T, Ohkura K, Nagamune H, Miyake Y. Histone-like DNA binding protein of Streptococcus intermedius induces the expression of pro-inflammatory cytokines in human monocytes via activation of ERK1/2 and JNK pathways. Cell Microbiol 2008;10:262-76.

84. Dennler S, Prunier C, Ferrand N, Gauthier JM, Atfi A. c-Jun inhibits transforming growth factor beta-mediated transcription by repressing Smad3 transcriptional activity. J Biol Chem 2000;275:28858-65.

85. Verrecchia F, Tacheau C, Wagner EF, Mauviel A. A central role for the JNK pathway in mediating the antagonistic activity of pro-inflammatory cytokines against transforming growth factor-beta-driven SMAD3/4-specific gene expression. JBiol Chem 2003;278:1585-93

86. Qian Y, Deng J, Geng L, Xie H, Jiang G, Zhou L, Wang Y, Yin S, Feng X, Liu J, Ye Z, Zheng S. TLR4 signaling induces B7-H1 expression through MAPK pathways in bladder cancer cells. Cancer Invest 2008;26:816-21.

87. Wesolowska A, Kwiatkowska A, Slomnicki L, Dembinski M Master A, Sliwa M, Franciszkiewicz K, Chouaib S, Kaminska B. Microglia-derived TGF-beta as an important regulator of glioblastoma invasion--an inhibition of TGF-beta-dependent effects by shRNA against human TGF-beta type II receptor. Oncogene 2008;27:918-30.

88. Markovic DS, Glass R, Synowitz M, Rooijen N, Kettenmann H. Microglia stimulate the invasiveness of glioma cells by increasing the activity of metalloprotease-2. J Neuropathol Exp Neurol 2005;64:754-62.

89. Li W, Graeber MB. The molecular profile of microglia under the 
influence of glioma. Neuro Oncol 2012;14:958-78.

90. Li W, Holsinger RM, Kruse CA, Flugel A, Graeber MB. The potential for genetically altered microglia to influence glioma treatment. CNS Neurol Disord Drug Targets 2013;12:750-62.

91. Smallie T, Ricchetti G, Horwood NJ, Feldmann M, Clark AR, Williams LM. IL-10 inhibits transcription elongation of the human TNF gene in primary macrophages. J Exp Med 2010;207:2081-8.

92. Wang P, Wu P, Siegel MI, Egan RW, Billah MM. Interleukin (IL)-10 inhibits nuclear factor kappa B (NF kappa B) activation in human monocytes. IL-10 and IL-4 suppress cytokine synthesis by different mechanisms. J Biol Chem 1995;270:9558-63.

93. Saccani A, Schioppa T, Porta C, Biswas SK, Nebuloni M, Vago L, Bottazzi B, Colombo MP, Mantovani A, Sica A. p50 nuclear factor-kappaB overexpression in tumor-associated macrophages inhibits M1 inflammatory responses and antitumor resistance. Cancer Res 2006;66:11432-40.

94. Cao S, Liu J, Chesi M, Bergsagel PL, Ho IC, Donnelly RP, Ma X. Differential regulation of IL-12 and IL-10 gene expression in macrophages by the basic leucine zipper transcription factor c-Maf fibrosarcoma. J Immunol 2002;169:5715-25.

95. Ashall L, Horton CA, Nelson DE, Paszek P, Harper CV, Sillitoe K, Ryan S, Spiller DG, Unitt JF, Broomhead DS, Kell DB, Rand DA, Sée V, White MR. Pulsatile stimulation determines timing and specificity of NF-kappaB-dependent transcription. Science 2009;324:242-6.

96. Nagasawa M. Epstein-Barr-Virus-Positive B-Cell Lymphoma of Recipient Origin Despite of the Elimination of Clonally EBV-Infected T Cells by Allogeneic Stem Cell Transplantation in a Patient with Chronic Active EBV Infection. Case Rep Transplant 2012;2012:164824

97. Hickey MJ, Malone CC, Erickson KL, Jadus MR, Prins RM, Liau LM, Kruse CA. Cellular and vaccine therapeutic approaches for gliomas. $J$ Transl Med 2010;8:100.

98. Gomez GG, Kruse CA. Isolation and Culture of Human Brain Tumor Cells. Meth Mol Med 2003;88:101-10.

99. Liau LM, Prins RM, Kiertscher SM, Odesa SK, Kremen TJ, Giovannone AJ, Lin JW, Chute DJ, Mischel PS, Cloughesy TF, Roth MD. Dendritic cell vaccination in glioblastoma patients induces systemic and intracranial T-cell responses modulated by the local central nervous system tumor microenvironment. Clin Cancer Res 2005; $11: 5515-25$

100. Fong B, Jin R, Wang X, Safaee M, Lisiero DN, Yang I, Li G, Liau LM, Prins RM. Monitoring of regulatory T cell frequencies and expression of CTLA-4 on T cells, before and after DC vaccination, can predict survival in GBM patients. PloS One 2012;7:e32614.

101. Hickey MJ, Malone CC, Erickson KE, Gomez GG, Young EL, Liau LM, Prins RM, Kruse CA. Implementing preclinical study findings to protocol design: translational studies with alloreactive CTL for gliomas. Am J Transl Res 2012;4:114-26.
102. Kruse CA, Rubinstein D. Cytotoxic T lymphocytes reactive to patient major histocompatibility proteins for therapy of recurrent primary brain tumors. In: Liau LM, Cloughesy TF, Becker DP, Bigner DD, editors; Brain tumor immunotherapy. Totowa: Humana Press 2001. p. 149-70.

103. Kruse CA, Cepeda L, Owens B, Johnson SD, Stears J, Lillehei KO. Treatment of recurrent glioma with intracavitary alloreactive cytotoxic T lymphocytes and interleukin-2. Cancer Immunol Immunother 1997;45:77-87.

104. Logg CR, Kasahara N. Retrovirus-mediated gene transfer to tumors: utilizing the replicative power of viruses to achieve highly efficient tumor transduction in vivo. Meth Mol Biol 2004;246:499-525.

105. Logg CR, Tai CK, Logg A, Anderson WF, Kasahara N. A uniquely stable replication-competent retrovirus vector achieves efficient gene delivery in vitro and in solid tumors. Human Gene Ther 2001;12:921-32.

106. Tai CK, Wang WJ, Chen TC, Kasahara N. Single-shot, multicycle suicide gene therapy by replication-competent retrovirus vectors achieves long-term survival benefit in experimental glioma. Mol Ther 2005;12:842-51.

107. Wang W, Tai CK, Kershaw AD, Solly SK, Klatzmann D, Kasahara N, Chen TC. Use of replication-competent retroviral vectors in an immunocompetent intracranial glioma model. Neurosurg Focus 2006;20:E25

108. Wang WJ, Tai CK, Kasahara N, Chen TC. Highly efficient and tumor-restricted gene transfer to malignant gliomas by replication-competent retroviral vectors. Human Gene Ther 2003; $14: 117-27$

109. Hickey MJ, Kasahara N, Mueller BM, Kruse CA. Combining cellular and gene therapy approaches for treatment of intracranial tumors. Oncoimmunology 2013;2:e25989.

110. Hickey MJ, Malone CC, Erickson KL, Lin A, Soto H, Ha ET, Kamijima S, Inagaki A, Takahashi M, Kato Y, Kasahara N, Mueller BM, Kruse CA. Combined alloreactive CTL cellular therapy with prodrug activator gene therapy in a model of breast cancer metastatic to the brain. Clin Cancer Res 2013;19:4137-48.

111. Morales A, Eidinger D, Bruce AW. Intracavitary Bacillus Calmette-Guerin in the treatment of superficial bladder tumors. 1976. J Urol 2002;167:891-3; discussion 893-5.

112. Böhle A, Brandau S. Immune mechanisms in bacillus Calmette-Guerin immunotherapy for superficial bladder cancer. J Urol 2003;170:964-9.

Cite this article as: Ha ET, Antonios JP, Soto H, Prins RM, Yang I, Kasahara N, Liau LM, Kruse CA. Chronic inflammation drives glioma growth: cellular and molecular factors responsible for an immunosuppressive microenvironment. Neuroimmunol Neuroinflammation 2014;1(2):66-76.

Source of Support: Nil. Conflict of Interest: No.

Received: 09-05-2014; Accepted: 21-07-2014 